\title{
BMJ Open Do parents recall and understand children's weight status information after BMI screening? A randomised controlled trial
}

\author{
Anna M Dawson, ${ }^{1}$ Rachael W Taylor, ${ }^{2}$ Sheila M Williams, ${ }^{3}$ Barry J Taylor, ${ }^{1}$ \\ Deirdre A Brown ${ }^{4}$
}

To cite: Dawson AM, Taylor RW, Williams SM, et al. Do parents recall and understand children's weight status information after BMI screening? A randomised controlled trial. BMJ Open 2014;4:e004481. doi:10.1136/bmjopen-2013004481

- Prepublication history and additional material is available. To view please visit the journal (http://dx.doi.org/ 10.1136/bmjopen-2013004481).

Received 15 November 2013 Revised 13 July 2014 Accepted 15 July 2014

CrossMark

For numbered affiliations see end of article.

Correspondence to Dr Rachael Taylor; rachael.taylor@otago.ac.nz

\section{ABSTRACT}

Objectives: As parents of young children are often unaware their child is overweight, screening provides the opportunity to inform parents and provide the impetus for behaviour change. We aimed to determine if parents could recall and understand the information they received about their overweight child after weight screening.

Design: Randomised controlled trial of different methods of feedback.

Setting: Participants were recruited through primary and secondary care but appointments took place at a University research clinic.

Participants and intervention: 1093 children aged 48 years were screened. Only overweight children $(n=271$, $24.7 \%$ ) are included in this study. Parents of overweight children were randomised to receive feedback regarding their child's weight using best practice care (BPC) or motivational interviewing (MI) at face-to-face interviews typically lasting 20-40 min. 244 (90\%) parents participated in a follow-up interview 2 weeks later to assess recall and understanding of information from the feedback session.

\section{Primary and secondary outcome measures:}

Interviews were audio-taped and transcribed verbatim before coding for amount and accuracy of recall. Scores were calculated for total recall and sub-categories of interest.

Results: Overall, $39 \%$ of the information was recalled (mean score 6.3 from possible score of 16). Parents given feedback via BPC recalled more than those in the Ml group (difference in total score $0.48 ; 95 \% \mathrm{Cl} 0.05$ to 0.92). Although $94 \%$ of parents were able to correctly recall their child's weight status, fewer than 10 parents could accurately describe what the measurements meant. Maternal education $(0.81 ; 0.25$ to 1.37$)$ and parental ratings of how useful they found the information $(0.19$; 0.04 to 0.35 ) were significant predictors of recall score in multivariate analyses.

Conclusions: While parents remember that their child's body mass index is higher than recommended, they are unable to remember much of the information and advice provided about the result.

Trial registration number: Australian New Zealand Clinical Trials Registry ACTRN12609000749202.

\section{Strengths and limitations of this study}

- First study to assess what parents remember and understand from a 20 to $40 \mathrm{~min}$ face-to-face session dedicated to discussing the weight status of their child.

- Recall and accuracy were studied extensively through the use of transcripts, which were transcribed verbatim, and coding according to an extensive coding schedule.

- Large $(n=244)$, demographically diverse sample of overweight children and their parents.

- Not originally designed to specifically test parental memory, and thus did not exhaustively prompt parents for complete recall.

\section{INTRODUCTION}

Approximately one in three children are overweight in New Zealand, ${ }^{1}$ a problem that is poorly recognised, particularly by parents..$^{2-4}$ It has therefore been suggested that routine consultations in primary care include measurement of body mass index (BMI) in an effort to improve recognition and awareness of excess weight during childhood. ${ }^{5}$

Although the primary care environment might seem suitable for routine screening given established relationships between families and their health practitioner, patients often present with multiple problems making it difficult for health practitioners to address each problem adequately within a standard consultation time. ${ }^{6}$ While adding measurement of height and weight may add little time to the overall appointment, discussion of overweight status, particularly for unsuspecting parents, is considerably more complicated. Whether parents have the ability to recall and understand this information, and thus potentially make the behavioural changes required, is unknown. 
The extent to which patients are able to recall their medical information has important implications for treatment adherence, patient satisfaction and subsequent health outcomes. ${ }^{78}$ In general, recall of medical information is low. ${ }^{9-12}$ Health information is often complex and may be incongruent with patients' perceptions. Furthermore, factors such as patient age, education, literacy levels, anxiety and stress impact upon a patient's ability to remember the information presented. ${ }^{13-16}$ Not surprisingly, several studies have demonstrated that parents recall pertinent details about their child's health (such as diagnoses or major injuries) more than peripheral details (such as tests completed in a consultation, prescriptions or follow-up appointments). ${ }^{15} 1718$

In the context of screening for overweight in children, it would appear that parents can recall important information, such as their child's weight status, following a posted letter. ${ }^{19}$ However, understanding of the results and BMI charts and/or percentiles is very low. ${ }^{20}$ To date, most evaluations of BMI screening simply measure whether parents recall receiving the letter. Only a few studies $^{20-22}$ have assessed whether parents understand BMI charts and percentiles, and none have done so after receiving BMI results in a face-to-face consultation, as would occur in a primary care setting. This is an important distinction as it may be that a letter of results provides an enduring memory cue or resource, which enables parents to better retain the information and refer to it if need be. Alternatively, a face-to-face session may enhance recall and understanding, given the opportunity to discuss the results and ask questions, thereby strengthening encoding of the information and creating stronger recall.

We recently examined whether motivational interviewing (MI) was an appropriate way of informing parents that their young child was overweight following BMI screening. ${ }^{23} 24$ Parents attended a second session 2 weeks later providing the opportunity for us to examine how well they recalled the information given in this face-to-face feedback session. Specifically, we examined how much information parents could recall from the BMI screening session, which types of information were more likely to be recalled, the accuracy of parental recall and how recall varied according to feedback style. Factors that may predict better recall performance were also explored. This manuscript represents a secondary data analysis from our main trial. ${ }^{24}$ While recall was not specified a priori as a variable of interest, it was considered a component of how well parents understood the feedback process. ${ }^{23}$

\section{SUBJECTS AND METHODS}

This manuscript presents data from a large randomised controlled study (RCT) which has been described in detail previously. ${ }^{23}$ In brief, MInT was a BMI screening initiative (phase 1) to recruit children into a 2-year family-based intervention in overweight children (phase
2). Phase 1 entailed a comparison of weight feedback delivered using best practice care (BPC) or MI whereas phase 2 compared a usual care intervention with a more intense intervention tailored to the needs of each family. Parents gave informed consent.

\section{Participants}

A total of 1093 children between the ages of 4 and 8 years, recruited from local primary care practices and secondary care clinics in Dunedin, New Zealand, were screened for overweight at a University research clinic. Parents were randomised to receive feedback (phase 1, screening) delivered using a BPC $(n=540)$ or MI approach $(\mathrm{n}=553)$ using random block lengths (Stata V.12.0, StataCorp, College Station, Texas, USA) after stratifying for practice, with sealed, opaque envelopes. Participants were blinded to randomisation condition. ${ }^{24}$ Only those parents with overweight children (BMI $>85$ th centile $)^{25}$ were eligible for the current study $(n=271$; figure 1). These parents were invited to participate in a recall interview at the University approximately 2 weeks later to discuss the feedback they received about their child's growth (phase 1, follow-up). Twenty parents declined participation in the recall interview. A further seven participants were excluded due to technical difficulties with audio recordings $(n=6)$ and one had brought the feedback booklet with them to the interview making them unsuitable for assessing recall of feedback.

\section{Procedures \\ Screening}

Parents (virtually all mothers, fathers $<2 \%$ ) completed a comprehensive online questionnaire assessing demographic characteristics including ethnicity, maternal education, an index of socioeconomic status (New Zealand deprivation index, NZDep2006 ${ }^{26}$ ) and maternal age. Parental concern about their child's weight and perception of their weight status was assessed using a 5-point Likert scale question (where $1=$ not at all concerned and $5=$ very concerned for levels of concern; and $1=$ underweight, $2=\mathrm{a}$ little underweight, $3=$ about right, $4=\mathrm{a}$ little overweight, $5=$ overweight for levels of perception). We calculated a discrepancy score to indicate the extent to which the parent under- or over-rated their child's weight status by comparing the parental perception of their child's weight status with their actual BMI classification (underweight $=<3$ rd centile, normal weight $=3$ rd -84 th centile, a little overweight $=85$ th -94 th centile, overweight $=\geq 95$ th centile). Scores of 1 or 2 for the perception of underweight were combined in this comparison. Duplicate anthropometric measurements (height, weight and waist) and blood pressure (BP) (Dinamap: GE Medical Systems, Waukesha, Wisconsin, USA) were obtained from children using standard techniques. All data report the mean values. BMI was calculated using CDC reference norms ${ }^{25}$ and waist $(\mathrm{cm})$ to height $(\mathrm{cm})$ ratio $(\mathrm{WHtR})$ was compared with recommendations from Ashwell and Hsieh. ${ }^{27}$ Researchers 


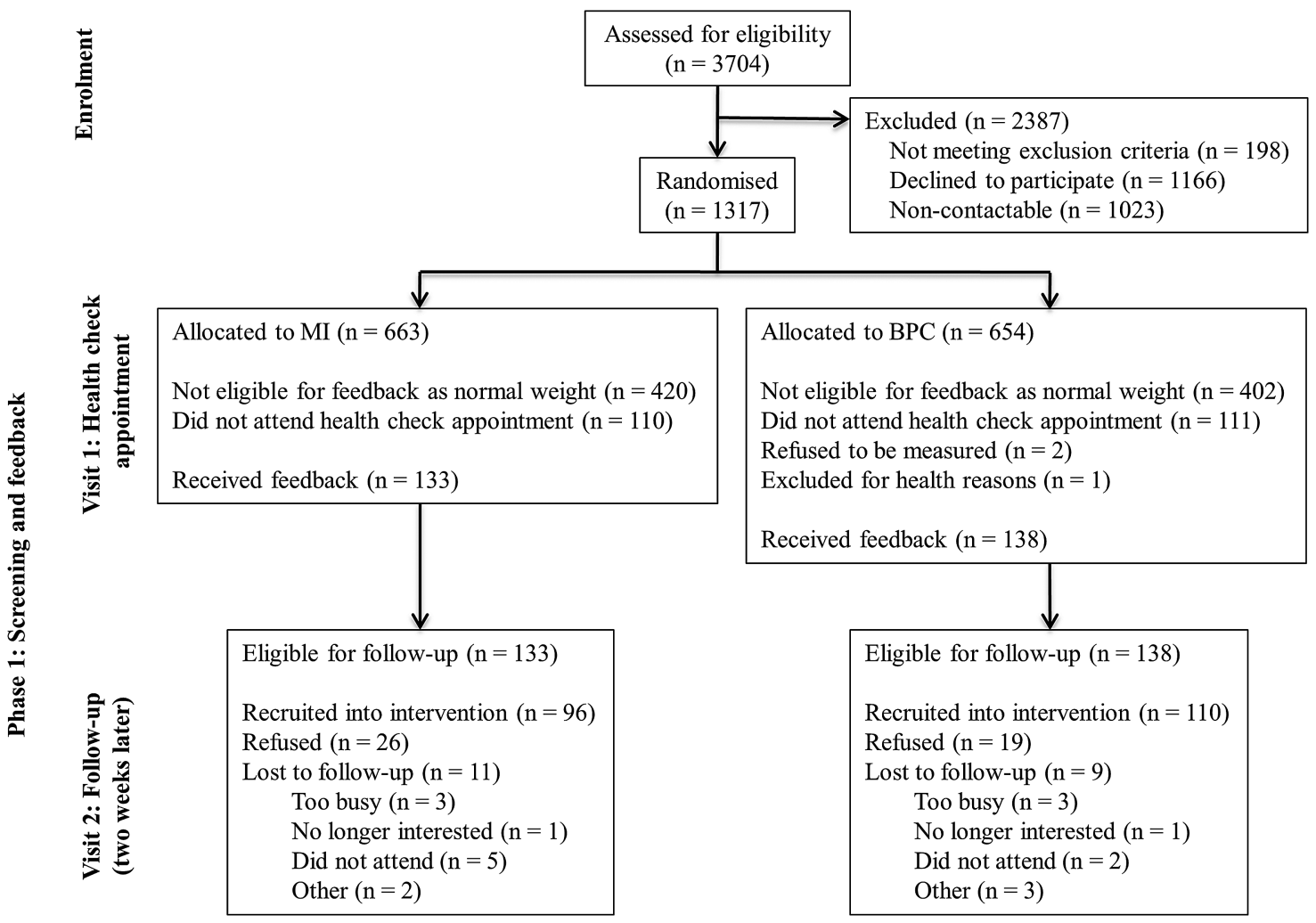

Figure 1 Participant flow throughout the study.

plotted BP, BMI and WHtR onto colour-coded charts relative to age and sex in a booklet that parents were able to take home. The booklet also included a glossary of key terms, a summary of the child's lifestyle behaviours (eg, physical activity, fruit and vegetable intake) as reported by parents, as well as current New Zealand guidelines for these behaviours. ${ }^{28}$

Feedback interview: Researchers explained each measure and then discussed the lifestyle behaviours. BMI and WHtR measurements were presented using a traffic light approach to avoid labelling the child as 'overweight' or 'obese'. Implications of each colour zone were explained in terms of how many children were in each zone, possible health consequences and the long-term risk of carrying excess weight associated with each zone. Researchers delivering the feedback were from different backgrounds (eg, dietetics, nutrition, exercise science). Therefore, researchers delivering BPC feedback $(n=2)$ received $6 \mathrm{~h}$ of general interviewing skills training and $6 \mathrm{~h}$ training on the feedback protocol. Researchers delivering MI feedback $(n=3)$ received approximately $40 \mathrm{~h}$ training in MI and the feedback protocol.

$B P C$ feedback condition: Researchers gave generic advice about healthy lifestyles, meaning that the primary focus of the BPC interview was on anthropometric results and discussion of the lifestyle behaviours. Interviews typically lasted $15 \mathrm{~min}$.

MI feedback condition: Parents were given information using an Elicit-Provide-Elicit (E-P-E) approach $^{29}$ that allowed researchers to check in with parents' prior knowledge before giving feedback. This approach also allowed parents the opportunity to explore the meaning and importance of the results. Therefore, in contrast to the BPC interview, the focus of the MI interview was on the implications of the health check results to the family. Interviews typically lasted $30 \mathrm{~min}$. All interviews were videotaped and transcribed verbatim so that accuracy of recall could be determined.

\section{Follow-up}

The recall interview took place approximately 2 weeks after the screening and feedback session and an independent interviewer $(n=3)$, not involved in the feedback process, interviewed the parents. Parents repeated aspects of the BMI screening questionnaire and completed a semi-structured interview (questions are presented in table 1). In summary, these assessed recall and usefulness of the information, and parental experience of the feedback. Interviews lasted approximately 10 $15 \mathrm{~min}$ and were audio recorded and later transcribed for coding by a professional transcriber blinded to the feedback group.

\section{Coding}

The number of pieces of information given at the feedback session was identified and defined by two authors (AMD, DAB). The first phase of the coding was developed a priori from the interview schedule, which was designed and developed prior to the study, based on the information we expected to elicit. The second phase of 


\section{Table 1 Recall interview questions}

\section{Free recall question}

1. What information were you given about your child's growth?

\section{Non-specific prompts}

Were you given any other information about your child at the initial session?

Tell me more about that...

What information were you given?

Specific prompt for implications

2. What were you told that the information means for him/her?

Additional interview questions-prompted recall

3. How easy was it to follow and use the information presented in the health check booklet?

$\begin{array}{ccccccc}1 & 2 & 3 & 5 & 6 & 7 \\ \text { Very easy } & & \text { Somewhat easy } & 4 & \text { Somewhat difficult } & & \text { Very difficult }\end{array}$

4. How useful did you find the information presented in the health check booklet?
Very useful
2
3
4
5
6
7
Somewhat useful
Not very useful
Not at all usefu height ratio?)

$$
1
$$

Very difficult
$2 \quad 3$

Somewhat difficult
5

Somewhat easy
7

Very easy

6. How useful did you find the traffic light system (green, orange and red zones) to explain your child's weight status?

$\begin{array}{cccccc}1 & 2 & 3 & 5 & 5 & 6\end{array}$

7. How did you feel about the way the information about your child's weight status was given to you?

8. I felt upset by the information given in the health check?

12

Not at all true

9. I felt upset

Not at all true

10. I felt it was useful to be given this information?
1
2

3

Not at all true
3

Somewhat true

5

\section{4}

Somewhat true

11. The information about my child's weight was unexpected?

1

Not at all true
2

12. I'm interested in your decision to tell/not tell your child.

13. If you did discuss the information with your child, what did you tell them?

14. How did your child react to this information?

15. Are there any other things we could do to improve the way our health check results are discussed with parents? Or any other comments?

the coding, involving the development of specific codes and weightings, was developed after the data had been collected and the researchers had become familiar with the categories of responses that parents gave (see online supplementary table S1). Lists of acceptable responses were developed and the coding framework was applied (initially collaboratively, then independently) to transcripts, and codes compared. Discrepancies were resolved through discussion and the coding rules were finalised. The pieces of information $(n=16)$, information categories $(n=6)$ and definitions are presented in table 2. Although 16 is a large number of discrete items of information to receive, the 6 categories were the main point of interest and the individual items were included to provide details on the type of information recalled. Scores were weighted according to their importance in the feedback interview. Weighting decisions were made through author discussion of the most important clinical messages delivered to parents. For example, the main result discussed was BMI; therefore, this was allocated the highest weighting of 4 from a maximum of 12.5. Only the weighted figures were used in analyses presented here, but results did not differ, whether weighted or unweighted scores were used (data not shown).

Coding was completed in two passes. The first pass assessed how much information was recalled. Coders identified relevant statements on the transcript and allocated a score under one or more categories. One statement could be coded in several categories (eg, "her BMI was in the overweight category' would gain a score for indicating that BMI was measured and for giving the BMI result). If a piece of information was mentioned more than once, only the first statement was allocated a score. As recall 
Table 2 Coding category definitions and possible scores

\begin{tabular}{|c|c|c|c|}
\hline $\begin{array}{l}\text { Coding } \\
\text { Categories }\end{array}$ & Definition & $\begin{array}{l}\text { Total number } \\
\text { of items }\end{array}$ & $\begin{array}{l}\text { Total weighted } \\
\text { score }\end{array}$ \\
\hline $\begin{array}{l}\text { Growth } \\
\text { measurement }\end{array}$ & $\begin{array}{l}\text { Recall of each measurement taken: height, weight, waist } \\
\text { circumference, body mass index (BMI) and waist to height ratio } \\
\text { (WhtR). }\end{array}$ & 5 & 2.5 \\
\hline Growth concept & $\begin{array}{l}\text { Recall reflecting knowledge or understanding of the concept of BMI- } \\
\text { looking at a person's weight in relation to their height (proportion) and } \\
\text { WhtR-a measure of how big they are around their waist, taking their } \\
\text { height into consideration }\end{array}$ & 2 & 1.5 \\
\hline Growth result & Recall of child's BMI and/or WhtR result & 2 & 4 \\
\hline $\begin{array}{l}\text { Growth } \\
\text { implication }\end{array}$ & $\begin{array}{l}\text { Recall of the implications of childhood overweight for health, severity } \\
\text { of problem, long-term weight problems, the need to act }\end{array}$ & 4 & 2 \\
\hline Blood pressure & $\begin{array}{l}\text { Recall that blood pressure was measured and the child's blood } \\
\text { pressure result }\end{array}$ & 2 & 1.5 \\
\hline Behavior & Recall of discussion of behavioural recommendations & 1 & 1 \\
\hline Total recall & & 16 & 12.5 \\
\hline
\end{tabular}

may be prompted by discussion that occurs later in the interview, recall of the implications associated with carrying excess weight was divided by stage of interview, into free and prompted recall (table 1). Recall of the other five information categories was not divided into free and prompted recall, as the majority of relevant information was recalled following question 1 , and the interview was not set up to prompt exhaustively as would be expected in a memory interview. Implications recalled in response to the first recall question and non-specific prompts were considered free recall. Implications recalled following a specific prompt or additional interview questions were considered prompted recall. The second coding pass identified whether the information recalled was accurate or not. Each piece of information identified in the first pass was compared with the transcript of the BMI feedback interview (ie, what was really discussed) and coded as correct or incorrect. Each recall interview transcript was coded by coder 1 (AMD) and 25\% (n=60) were coded by coder $2(\mathrm{DAB})$. AMD also recoded a subset of the interviews $(12 \%, n=30)$ to check for drift. $\kappa$ Values for inter- and intra-reliability were moderate to excellent ${ }^{30}$ $(0.48-0.96)$.

\section{Data analysis}

Linear regression was conducted to examine the overall effects of interview condition, recall interviewer and time between feedback and recall interview. To examine the amount of information recalled, scores were converted to a proportion of the total number of items in each category and regression was used to compare the relative frequencies of information category (withinsubjects factor) and the interaction of feedback condition (between-subjects factor). Accuracy was calculated as the number who correctly recalled the information from (1) just those who actually mentioned each type of information and (2) from all parents. Thus accuracy for the former calculation reflects errors of commission, whereas using the total number of parents as the denominator also includes errors of omission. Accuracy was analysed using a two-group difference in proportion test to detect any difference between the two feedback conditions. A mixed model was used to compare recall of the meaning of results by stage of interview (withinsubjects factor) and feedback condition (betweensubjects factor). The model included an interaction term to find out whether the type of information (lifestyle changes vs implications) was different in the MI and BPC groups. To investigate which factors are associated with better recall, variables were analysed using multiple linear regression. Variables with $\mathrm{p}<0.2$ in the univariate model were included in the multivariate models. To adjust for feedback condition and time between feedback and recall session, these variables were also included in the multivariate models. Data were also adjusted for clustering within families given that one family enrolled three overweight siblings and nine families enrolled two siblings.

The larger MInT study from which these data are derived is adequately powered, as it required a minimum of 250 participants to detect the main outcomes of interest, with a final sample size of $271 .^{24}$ No sample size calculations were performed prior to analysis for this paper, as it was a secondary data analysis. All data were analysed using Stata V.13.1 (StataCorp, College Station, Texas, USA). As missing data were less than $1.5 \%$ (43 of 2928 data points) we have presented analyses for the available data.

\section{RESULTS}

Table 3 presents the characteristics of the overall sample and according to participation. Parents who did not participate in recall interviews $(n=27)$ had children who did not differ from children who did participate $(n=244)$ in terms of age, sex, ethnicity, household deprivation, 
Table 3 Baseline characteristics of the study population

\begin{tabular}{|c|c|c|c|c|}
\hline & $\begin{array}{l}\text { Total } \\
(n=271)\end{array}$ & $\begin{array}{l}\text { Participants } \\
(n=244)\end{array}$ & $\begin{array}{l}\text { Non-participants } \\
(\mathrm{n}=27)\end{array}$ & $\begin{array}{l}\text { Difference or OR } \\
(95 \% \mathrm{Cl})\end{array}$ \\
\hline Girls n (\%) & $150(55)$ & $135(55)$ & $15(56)$ & $-0.99(-2.21$ to 0.44$) \dagger$ \\
\hline Age (years) & $6.4(1.4)$ & $6.4(1.4)$ & $6.3(1.7)$ & $0.12(-0.52 \text { to } 0.08)^{*}$ \\
\hline \multicolumn{5}{|l|}{ Ethnicity ${ }^{\mathrm{a}} \mathrm{n}(\%)$} \\
\hline New Zealand European and others & $200(74)$ & $182(75)$ & $18(67)$ & 1.00 \\
\hline Maori & $50(19)$ & $43(18)$ & $7(26)$ & $0.61(0.24$ to 1.55$) \dagger$ \\
\hline Pacific & $20(7)$ & $18(7)$ & $2(7)$ & $0.89(0.18$ to 4.19$) \dagger$ \\
\hline Household deprivation ${ }^{\mathrm{b}}$ & $5.1(2.9)$ & $5.1(2.6)$ & $5.0(2.6)$ & $0.06(-1.12 \text { to } 0.99)^{*}$ \\
\hline Maternal age (years) ${ }^{c}$ & $37.0(5.8)$ & $37.0(5.7)$ & $36.7(7.1)$ & $0.00(-0.01 \text { to } 0.01)^{*}$ \\
\hline \multicolumn{5}{|l|}{ Maternal education ${ }^{d}$} \\
\hline Some secondary school n (\%) & $86(32)$ & $79(33)$ & $7(12)$ & 1.00 \\
\hline $\begin{array}{l}\text { Completed secondary school or tertiary } \\
\text { education (not University) }\end{array}$ & $91(34)$ & $79(33)$ & $12(44)$ & $0.58(0.21$ to 1.55$) \dagger$ \\
\hline University degree & $91(34)$ & $83(34)$ & $8(30)$ & $0.92(0.32$ to 2.64$) \dagger$ \\
\hline Maternal $\mathrm{BMI}^{\mathrm{e}}\left(\mathrm{kg} / \mathrm{m}^{2}\right)$ & $29.1(6.2)$ & $29.2(6.4)$ & $28.6(4.4)$ & $0.63(-1.25 \text { to } 2.50)^{*}$ \\
\hline Height (cm) & $120.7(11.2)$ & $120.9(11.0)$ & $118.8(12.4)$ & $2.09(-2.76 \text { to } 6.94)^{*}$ \\
\hline Weight (kg) & $28.7(7.8)$ & $28.9(7.8)$ & $27.5(7.4)$ & $1.39(-1.52 \text { to } 4.32)^{*}$ \\
\hline BMI z-score & $1.61(0.45)$ & $1.61(0.46)$ & $1.56(0.36)$ & $0.04(-0.10 \text { to } 0.19)^{*}$ \\
\hline
\end{tabular}

maternal BMI, maternal education, height, weight or BMI z-score. Reasons given for non-participation included too busy $(n=8)$, equipment malfunction $(n=6)$, no reason given $(n=3)$, families were moving out of town $(n=2)$, non-contactable $(n=2)$ or missed multiple appointments $(n=2)$, child did not want to $(n=1)$, traumatised by recent Christchurch earthquakes $(n=1)$, belief that the child was not overweight $(n=1)$ and brought the feedback booklet to the recall interview $(n=1)$.

Table 4 presents the mean number of items recalled and weighted score by information category. On average, participants recalled only 6.3 out of the 16 (39\%) pieces of information that they were given at the feedback session. There was no difference in total recall score by recall interviewer (difference, 95\% CI: $0.37,-0.16$ to $0.44)$, but total recall score decreased by 0.03 (95\% CI -0.05 to -0.004 ) for each extra day between the feedback and recall interview $(\mathrm{p}=0.029)$. Therefore, analyses have been adjusted for feedback condition (MI or BPC) and time between interviews (days). There was a significantly higher total recall score for those in the BPC condition $(\mathrm{M}=6.01, \mathrm{SD}=1.42$ from a total possible score of 12.5) compared with the $\mathrm{MI}$ condition $(\mathrm{M}=5.55, \mathrm{SD}=1.83)$ (difference 0.48 (95\% CI 0.05 to 0.92$), \mathrm{p}=0.030)$.

Table 5 reports the number of people who recalled each category of information and illustrates that while very few parents recalled information about their child's fat distribution (28\%) or blood pressure findings $(21 \%)$, virtually every parent recalled that their child had a high BMI $(97 \%)$. However, it is clear that many parents did not know what this actually meant, whether in terms of understanding the concept of these measurements (only $26 \%$ could say that BMI was a measure of weight in relation to height) or, more importantly, the implications of a high BMI (such as carrying excess weight into adolescence). Fifteen per cent of parents had no idea of the implications of their child having a high BMI and a further $38 \%$ recalled only one of four possible

Table 4 Mean (SD) number of items recalled and weighted score, reported by information category

\begin{tabular}{|c|c|c|c|c|}
\hline \multirow[b]{2}{*}{ Information category } & \multicolumn{2}{|c|}{ Total sample $(n=244)$} & \multirow[b]{2}{*}{$\begin{array}{l}\text { MI ( } n=121) \\
\text { Weighted scores M (SD) }\end{array}$} & \multirow{2}{*}{$\begin{array}{l}\text { BPC }(n=122) \\
\text { Weighted scores } \\
\text { M (SD) }\end{array}$} \\
\hline & $\begin{array}{l}\text { Number of items } \\
\text { M (SD) }\end{array}$ & $\begin{array}{l}\text { Weighted scores } \\
\text { M (SD) }\end{array}$ & & \\
\hline Growth measurement & $2.5(1.39)$ & $1.2(0.69)$ & $1.16(0.77)$ & $1.28(0.61)$ \\
\hline Growth concept & $0.3(0.51)$ & $0.3(0.46)$ & $0.19(0.42)$ & $0.36(0.49)$ \\
\hline Growth result & $0.5(0.75)$ & $2.9(0.75)$ & $2.84(0.75)$ & $2.87(0.76)$ \\
\hline Growth implication & $1.5(0.90)$ & $0.8(0.49)$ & $0.83(0.49)$ & $0.66(0.47)$ \\
\hline Blood pressure & $0.5(0.75)$ & $0.4(0.56)$ & $0.32(0.55)$ & $0.36(0.57)$ \\
\hline Behaviour & $0.3(0.46)$ & $0.3(0.46)$ & $0.19(0.40)$ & $0.45(0.50)$ \\
\hline Total recall & $6.3(2.28)$ & $5.8(1.66)$ & 5.55 (1.83) & $6.01(1.42)$ \\
\hline
\end{tabular}


implications that they were told when they were given their child's BMI result. Logistic regression demonstrated a significant interaction between the type of information recalled (eg, BMI result) and feedback condition (BPC or MI) $(\mathrm{p}<0.01)$. Further examination demonstrated that those in the BPC condition were more likely to report that lifestyle behaviours had been discussed (mean difference in score 0.27 from total possible score of $1.0,95 \%$ CI 0.14 to $0.40, \mathrm{p}<0.01$ ), whereas the implications of the BMI results were more likely to be reported by those in the MI condition (mean difference in score 0.14 from a total possible score of $2.0,95 \%$ CI 0.01 to $0.27, \mathrm{p}=0.02)$.

Table 5 also presents the proportion of parents who correctly recalled each type of information. As mentioned $97 \%(n=238)$ of parents remembered their child had a high BMI and $97 \%(\mathrm{n}=230)$ of these or $94 \%$ of parents overall were accurate in their recollection. Parents recalled their child's BP and WHtR results less often ( $n=51-68$ parents). Estimates of accuracy were based on errors of commission (ie, parents who reported the information but did so incorrectly), of which 86-97\% accurately recalled the information. When we included errors of omission (ie, parents who left the information out of their account), accuracy was substantially lower (19-25\%). Although the number of parents recalling what high BMI meant for their child (implications) was considerably lower, those parents who did recall implications were generally very accurate (ie, child was overweight and was more at risk of carrying this weight into adolescence), being correct $83-97 \%$ of the time. In contrast, the concept of BMI or WHtR (ie, whether the child's weight and height are in proportion, for their age) was poorly understood with only seven parents correctly recalling the concept of BMI and three parents correctly recalling WHtR. Interestingly, feedback condition made no difference to the accuracy of parental recall.

Not surprisingly, there was significantly higher recall of the meaning of results following prompting (mean difference 0.28 from a total possible score of $2,95 \%$ CI 0.18 to $0.38, \mathrm{p}<0.01$ ). This was particularly apparent for those in the MI group who showed a larger increase in meaning recall after prompting $(\mathrm{M}=0.55, \mathrm{SD}=0.45)$ than BPC $(\mathrm{M}=0.40, \mathrm{SD}=0.41)$ (interaction term $0.14,0.00$ to $0.28, \mathrm{p}=0.04)$.

Table 6 presents the models for the association between total recall scores and predictors of interest. As the univariate models demonstrated that both time between feedback and recall session $(\mathrm{p}=0.029)$ and feedback condition $(p=0.030)$ were significantly related to total recall score, only the multivariate models are discussed here. After adjustment for these two variables, mothers with a university education had higher recall scores (difference, $95 \%$ CI $0.76,0.20$ to 1.32 ) than less educated mothers, whereas no differences were observed for child ethnicity or BMI z-score, maternal age or maternal BMI. Most variables of interest associated with the total recall score appeared to be related to the experience of the feedback process. Having a larger discrepancy between perceived and actual weight was associated with lower recall scores $(-0.44,-0.76$ to

Table 5 Parent recall of each type of information in the overall sample and by feedback condition

\begin{tabular}{|c|c|c|c|c|c|c|c|c|c|}
\hline \multirow[b]{2}{*}{ Information category } & \multicolumn{3}{|l|}{ Total recall (\%) } & \multicolumn{3}{|c|}{ Correct recall* (\%) } & \multicolumn{3}{|c|}{ Correct recall† (\%) } \\
\hline & $\begin{array}{l}\text { Total sample } \\
n=244\end{array}$ & $\begin{array}{l}M I \\
n=121\end{array}$ & $\begin{array}{l}\text { BPC } \\
n=123\end{array}$ & $\begin{array}{l}\text { Total } \\
\text { sample }\end{array}$ & MI & BPC & $\begin{array}{l}\text { Total } \\
\text { sample }\end{array}$ & MI & BPC \\
\hline \multicolumn{10}{|l|}{ Results } \\
\hline BMI result & $238(97)$ & $119(98)$ & $119(97)$ & $230(97)$ & $115(97)$ & $115(97)$ & $230(94)$ & $115(95)$ & $115(93)$ \\
\hline WHtR result & $68(28)$ & $30(25)$ & $38(31)$ & $61(90)$ & $26(87)$ & $35(92)$ & $61(25)$ & $26(21)$ & $35(28)$ \\
\hline Blood pressure & $51(21)$ & $22(18)$ & $29(24)$ & 47 (92) & $19(86)$ & $28(97)$ & 47 (19) & $19(17)$ & $28(23)$ \\
\hline \multicolumn{10}{|l|}{ Meaning of results } \\
\hline $\begin{array}{l}0 \text { implications } \\
\text { recalled }\end{array}$ & $37(15)$ & $11(9)$ & $26(21)$ & - & - & - & - & - & - \\
\hline $\begin{array}{l}1 \text { implication } \\
\text { recalled }\end{array}$ & $92(38)$ & $47(39)$ & $45(36)$ & $85(92)$ & $43(91)$ & $42(93)$ & $85(35)$ & $43(36)$ & $42(34)$ \\
\hline $\begin{array}{l}2 \text { implications } \\
\text { recalled }\end{array}$ & $75(31)$ & $40(33)$ & $35(29)$ & $67(89)$ & $38(95)$ & $29(83)$ & $67(27)$ & $38(31)$ & $29(24)$ \\
\hline $\begin{array}{l}3 \text { or } 4 \text { implications } \\
\text { recalled }\end{array}$ & 40 (16) & $23(19)$ & $17(14)$ & $33(83)$ & $19(83)$ & $14(83)$ & $33(14)$ & $19(16)$ & $14(11)$ \\
\hline Behaviour discussion & $80(33)$ & $24(20)$ & $56(46)$ & - & - & - & - & - & - \\
\hline \multicolumn{10}{|l|}{ Concepts discussed } \\
\hline BMI concept & $63(26)$ & $21(17)$ & $42(34)$ & $7(11)$ & $3(14)$ & $4(10)$ & $7(3)$ & $3(2)$ & $4(3)$ \\
\hline WHtR concept & $11(5)$ & $5(4)$ & $6(5)$ & $3(27)$ & $0(0)$ & $3(50)$ & $3(0)$ & $0(0)$ & $3(2)$ \\
\hline
\end{tabular}


Table 6 Models for the association between total recall and predictors of interest

\begin{tabular}{|c|c|c|c|}
\hline Variable & $\begin{array}{l}\text { Univariate model } \\
(95 \% \mathrm{Cl})\end{array}$ & $\begin{array}{l}\text { Multivariate model } 1 \\
(95 \% \mathrm{Cl})\end{array}$ & $\begin{array}{l}\text { Multivariate model } 2 \\
(95 \% \mathrm{Cl})\end{array}$ \\
\hline \multicolumn{4}{|l|}{ Maternal education } \\
\hline Tertiary† & $0.30(-0.25$ to 0.86$)$ & $0.30(-0.25$ to 0.84$)$ & $0.30(-0.30$ to 0.85$)$ \\
\hline University degree† & $0.82(0.27 \text { to } 1.38)^{\star}$ & $0.76(0.20 \text { to } 1.32)^{\star}$ & $0.81(0.25 \text { to } 1.37)^{\star}$ \\
\hline \multicolumn{4}{|l|}{ Ethnicity } \\
\hline Maorił & $-0.61(-1.17 \text { to }-0.05)^{*}$ & $-0.52(-1.09$ to 0.04$)$ & \\
\hline Pacific $¥$ & $-0.30(-1.10$ to 0.51$)$ & $-0.30(-1.08$ to 0.48$)$ & \\
\hline Maternal BMI & $-0.01(-0.05$ to 0.02$)$ & $-0.01(-0.04$ to 0.02$)$ & \\
\hline Maternal age & $0.02(-0.02,0.06)$ & $0.02(-0.02$ to 0.06$)$ & \\
\hline Child BMI (z-score) & $0.19(-0.31$ to 0.71$)$ & $0.12(-0.37$ to 0.61$)$ & \\
\hline Parental concern before feedback & $0.27(0.06 \text { to } 0.47)^{\star}$ & $0.20(-0.01$ to 0.42$)$ & $0.10(-0.13$ to 0.33$)$ \\
\hline $\begin{array}{l}\text { Discrepancy between perceived and actual } \\
\text { weight }\end{array}$ & $-0.52(-0.84 \text { to }-0.21)^{*}$ & $-0.44(-0.76 \text { to }-0.14)^{*}$ & $-0.23(-0.58$ to 0.11$)$ \\
\hline Weight information unexpected & $-0.10(-0.19 \text { to }-0.002)^{*}$ & $-0.09(-0.18$ to 0.01$)$ & $-0.03(-0.13$ to 0.07$)$ \\
\hline $\begin{array}{l}\text { Understand information presented in } \mathrm{HC} \\
\text { booklet }\end{array}$ & $0.28(0.06 \text { to } 0.49)^{*}$ & $0.29(0.07 \text { to } 0.50)^{*}$ & $0.19(-0.04$ to 0.42$)$ \\
\hline $\begin{array}{l}\text { Usefulness of information presented in } \mathrm{HC} \\
\text { booklet }\end{array}$ & $0.22(0.07 \text { to } 0.37)^{*}$ & $0.20(0.04 \text { to } 0.35)^{*}$ & $0.19(0.04 \text { to } 0.35)^{*}$ \\
\hline $\begin{array}{l}\text { Time between feedback and recall session } \\
\text { (days) }\end{array}$ & $-0.03(-0.05 \text { to }-0.004)^{*}$ & & $-0.02(-0.04$ to 0.01$)$ \\
\hline Feedback condition & $0.48(0.05 \text { to } 0.92)^{*}$ & & $0.28(-0.18$ to 0.73$)$ \\
\hline \multicolumn{4}{|c|}{$\begin{array}{l}\text { Estimates refer to the difference in total recall weighted score (from possible of } 12.5 \text { ) explained by each predictor of interest. } \\
\text { Multivariate model } 1 \text { estimates are adjusted for time between feedback and recall interview and feedback condition. } \\
\text { Multivariate model } 2 \text { estimates are adjusted for all other variables in the model. } \\
{ }^{*} p<0.05 \text {. } \\
\text { †Reference group was some secondary school. } \\
\text { †Reference group was New Zealand European and others. } \\
\text { BMI, body mass index; HC, health check. }\end{array}$} \\
\hline
\end{tabular}

-0.14). Conversely, understanding the information presented in the feedback process $(0.29,0.07$ to 0.50$)$ or finding it useful $(0.20,0.04$ to 0.35$)$ were both associated with higher recall scores to a similar degree. Once all significant variables were entered in multivariate model 2 , only university maternal education $(0.81,0.25$ to 1.37$)$ and finding the information useful $(0.19,0.04$ to 0.35$)$ remained independent predictors of total recall score.

\section{DISCUSSION}

Our study demonstrated that although parents were only able to recall $39 \%$ of the information that was given to them at the BMI screening session, virtually all $(97 \%)$ recalled that their child was overweight. Our findings are consistent with previous research demonstrating that while overall recall of medical information is poor, ${ }^{9}$ parents are good at recalling important details such as their child's diagnosis ${ }^{15}$ or weight status. ${ }^{19}$ In contrast, information from other categories was not as readily reported and, in particular, concepts were poorly understood, with less than $50 \%$ of parents able to accurately describe what was done. These findings are consistent with the attentional narrowing hypothesis which suggests that the most salient information is attended to, leaving less attention for peripheral information. ${ }^{31}$ Given the poor recognition of overweight in children, it is likely that receiving such feedback will elicit distress in some people, which may accentuate attentional narrowing. ${ }^{31} 32$ However, it is important to note that the child's actual BMI was supported by a graph that parents were able to take home, and therefore may have aided recall of the key results, similar to BMI screening studies, which provide results in a letter that parents are able to refer back to. In contrast, the meaning of the BMI result was discussed in the session but was not supported by a take home message. While the provision of take home written information to aid recall of medical information has produced inconsistent results, ${ }^{7}$ there is some evidence to suggest that simple pictorial messages can aid recall. ${ }^{33}$ It is also important to note that unfamiliar concepts (such as the waist to height ratio measurement) were also supported by a take home visual and yet were poorly recalled. This may suggest that a take home message may not be sufficient to promote recall of unfamiliar concepts. Furthermore, in contrast to typical healthcare appointments, the feedback was given in an environment that minimised distractions (eg, the presence of the child or other siblings), potentially optimising the ability of parents to process the information being communicated.

Findings from the current study suggest that parents have limited capacity for processing a large amount of information and although they are able to remember some key pieces of information (that their child was overweight), important details were forgotten (such as why being an overweight child is a concern). While it 
could be argued that six categories of information is an unrealistic target, a considerable amount of time was spent within the interviews on BMI and what it means for health; more than would be spent during a typical primary care consultation. This has important implications for including BMI screening within routine healthcare, especially if the information is unexpected. Thus, health professionals need to limit the amount of information given in one session, provide personalised takehome information, or use multiple sessions to assess gaps in patient recall or understanding and provide clarification, especially if the information is unexpected or includes unfamiliar concepts.

Despite our best efforts to present information to promote optimal recall and understanding ${ }^{7}$ (spending a significant portion of time on the key message (BMI and health), providing pictorial information and providing simple non-technical explanations), ${ }^{7}$ our findings suggest that the implications were poorly recalled and concepts were poorly understood. While a diagnosis is important, it is not meaningful without an understanding of the implications and a clear treatment pathway. This is particularly relevant in primary care, where doctors are often reluctant ${ }^{34}$ to discuss childhood overweight and unsure how to communicate this information to families. ${ }^{35}$ This may inadvertently lead to ambiguous information or brief communication, making it easy for parents to become confused about the messages they are being given, particularly if the information conflicts with parental beliefs. Poor understanding also has implications for the transfer of this information beyond the direct medical setting and into the child's wider context. For example, if parents are unable to understand what their child's results mean, there is the potential for miscommunication with significant people in the child's life who might need to be involved in changing lifestyle factors.

Literature examining parental recall of child weight status information is very limited ${ }^{192036}$ and no studies appear to have assessed recall and understanding of BMI information and related concepts following a targeted face-to-face interview. Johnson and colleagues ${ }^{19}$ investigated parent reactions to a screening programme and included measures of recall of the information provided in a BMI results letter. Consistent with the current study, important information was recalled well (eg, 94\% of the parents recalled their child's weight category), and other details were less likely to be recalled (eg, measurements). However, reports of parental accuracy were lower than those observed in the current study. This may have arisen because of different methods of informing parents (letter vs face-to-face) or due to the more stringent accuracy classification used by Johnson $e t$ al. ${ }^{19}$

Although it may seem surprising that parents receiving BPC feedback were able to remember more than those who received MI, more structured and specific information is more likely to be remembered. ${ }^{73}$ The BPC interview was highly structured and the advice given to parents to achieve lifestyle guidelines was very specific (eg, change high fat to low fat milk), whereas the MI session, reflecting the intention of $\mathrm{MI}^{38}$ was not structured, with research assistants intentionally avoiding giving specific advice. As the MI sessions were twice as long as the BPC sessions, it is also possible that the additional time spent on the exploration of the meaning and implication of results took focus away from the central details of the message, resulting in lower recall of the information.

Higher maternal education was related to improved overall recall, consistent with the literature in other health contexts. ${ }^{714}$ While a relationship between recall and child and maternal BMI, ${ }^{19}$ ethnicity ${ }^{19}$ and age ${ }^{39}$ have previously been suggested, they were unrelated in this study. Here, beliefs about weight played a more important role: parents who found the information unexpected or did not understand the feedback process or find it useful, had lower recall. In contrast, those who were already concerned about their child's weight had higher overall recall. These findings are consistent with the hypothesis that memory is heightened for information that is consistent with one's current beliefs ${ }^{40}$ and has implications for health practitioners giving parents results that they may not expect. Prior to delivering feedback, health practitioners may benefit from assessing parents' expectations, concerns and current knowledge, to assist in prioritising and explaining results that may not align with these.

This study examined recall and understanding in a large sample of families with overweight children. This study was not originally constructed to assess parental memory, and as such it was not set up to exhaustively prompt parents for complete recall. It is possible that had we interviewed differently, parents may have recalled more information. However, much of the information used in this interview was based on free recall, which is particularly relevant in this context as it likely reflects the information that is most salient and easily accessible to parents.

In summary, our findings appear to be the first to examine parental recall of BMI and growth information following a BMI screening and face-to-face feedback session. While our results suggest that parents were able to remember their child's overweight diagnosis very well, $61 \%$ of the information was forgotten. This finding suggests that the inclusion of BMI screening within current appointments may negatively impact parental ability to remember and understand this information. In addition, the way that the information is given, and parental education, values and expectations, were associated with recall of the information and therefore suggest that health professionals need to be aware of these factors when discussing results with parents.

\section{Author affiliations}

${ }^{1}$ Department of Women's and Children's Health, Dunedin School of Medicine, University of Otago, Dunedin, New Zealand

${ }^{2}$ Department of Medicine, Dunedin School of Medicine, University of Otago, Dunedin, New Zealand 
${ }^{3}$ Department of Preventive and Social Medicine, Dunedin School of Medicine, University of Otago, Dunedin, New Zealand

${ }^{4}$ School of Psychology, Victoria University of Wellington, Wellington, New Zealand

Contributors AMD contributed to study design, undertook data collection, coded the transcripts, produced the first and subsequent drafts of the paper and approved the final manuscript as submitted. RWT was the principal investigator of the project and was responsible for study design, monitored data collection, critically reviewed and revised the manuscript, and is the guarantor. SMW contributed to study design, completed statistical analysis, critically reviewed manuscript and approved the final manuscript as submitted. BJT contributed to study design, critically reviewed and revised the manuscript and approved the final manuscript as submitted. DAB contributed to study design, supervised research staff, provided reliability coding, critically reviewed and revised the manuscript, and approved the final manuscript as submitted.

Funding This research was supported by the Health Research Council of New Zealand (09/087B).

Competing interests AMD is supported by the Freemasons New Zealand and RWT is funded by the KPS research fellowship.

Ethics approval Ethical approval was obtained from the Lower Regional South Ethics Committee (LRS/09/09/039).

Provenance and peer review Not commissioned; externally peer reviewed.

Data sharing statement No additional data are available.

Open Access This is an Open Access article distributed in accordance with the Creative Commons Attribution Non Commercial (CC BY-NC 3.0) license, which permits others to distribute, remix, adapt, build upon this work noncommercially, and license their derivative works on different terms, provided the original work is properly cited and the use is non-commercial. See: http:// creativecommons.org/licenses/by-nc/3.0/

\section{REFERENCES}

1. Parnell W, Scragg R, Wilson $\mathrm{N}$, et al. NZ food NZ children: key results of the 2002 National Children's Nutrition Survey. Wellington, New Zealand: Ministry of Health, 2003:1-267.

2. Doolen J, Alpert PT, Miller SK. Parental disconnect between perceived and actual weight status of children: a metasynthesis of the current research. J Am Acad Nurse Pract 2009;21:160-6.

3. Campbell MW, Williams J, Hampton A, et al. Maternal concern and perceptions of overweight in Australian preschool-aged children. Med J Aust 2006;184:274-7.

4. Carnell S, Edwards $\mathrm{C}$, Croker $\mathrm{H}$, et al. Parental perceptions of overweight in 3-5 y olds. Int J Obes (Lond) 2005;29:353-5.

5. Waters E, Swinburn B, Seidell J, et al. Preventing childhood obesity evidence, policy, and practice. Wiley-Blackwell, 2010:306.

6. Fortin M, Soubhi H, Hudon C, et al. Multimorbidity's many challenges. BMJ 2007;334:1016-17.

7. Watson PWB, McKinstry B. A systematic review of interventions to improve recall of medical advice in healthcare consultations. $J R$ Soc Med 2009;102:235-43.

8. Zolnierek KBH, DiMatteo MR. Physician communication and patient adherence to treatment: a meta-analysis. Med Care 2009;47:826-34.

9. Kessels RPC. Patients' memory for medical information. J $R$ Soc Med 2003;96:219-22.

10. Jansen J, Butow PN, van Weert JCM, et al. Does age really matter? Recall of information presented to newly referred patients with cancer. J Clin Oncol 2008;26:5450-7.

11. Godwin $Y$. Do they listen? A review of information retained by patients following consent for reduction mammoplasty. Br J Plast Surg 2000;53:121-5.

12. Pesudovs K, Luscombe CK, Coster DJ. Recall from informed consent counselling for cataract surgery. J Law Med 2006;13:496-504.

13. Jansen J, van Weert JC, de Groot J, et al. Emotional and informational patient cues: the impact of nurses' responses on recall. Patient Educ Couns 2010;79:218-24.
14. Selic $P$, Svab I, Repolusk M, et al. What factors affect patients' recall of general practitioners' advice? BMC Fam Pract 2011;12:141.

15. Moon RY, Cheng TL, Patel KM, et al. Parental literacy level and understanding of medical information. Pediatrics 1998;102:e25.

16. McCarthy DM, Waite KR, Curtis LM. What did the doctor say? Health literacy and recall of medical instructions. Med Care 2012;50:277-82.

17. Grover G, Berkowitz CD, Lewis RJ. Parental recall after a visit to the emergency department. Clin Pediatr (Phila) 1994;33:194-201.

18. Pless CE, Pless IB. How well they remember: the accuracy of parent reports. Arch Pediatr Adolesc Med 1995;149:553-8.

19. Johnson SB, Pilkington LL, Lamp C, et al. Parent reactions to a school-based body mass index screening program. J Sch Health 2009;79:216-23.

20. Woolford SJ, Clark SJ, Lumeng JC, et al. Maternal perspectives on growth and nutrition counseling provided at preschool well-child visits. J Natl Med Assoc 2007:99:153-8.

21. Ben-Joseph EP, Dowshen SA, Izenberg N. Do parents understand growth charts? A national, internet-based survey. Pediatrics 2009;124:1100-9.

22. Oettinger MD, Finkle JP, Esserman D, et al. Color-coding improves parental understanding of body mass index charting. Acad Pediatr 2009:9:330-8.

23. Taylor R, Brown D, Dawson A, et al. Motivational interviewing for screening and feedback and encouraging lifestyle changes to reduce relative weight in 4-8-year-old children: design of the MInT study. BMC Public Health 2010;10:271.

24. Dawson AM, Brown DA, Cox A, et al. Using motivational interviewing for weight feedback to parents of young children. $J$ Paediatr Child Health 2014;50:461-70.

25. Kuczmarski R, Ogden C, Guo S, et al. 2000 CDC growth charts for the United States: methods and development. Data from the National Health Survey. Vital Health Stat 11 2002;246:1-190.

26. White P, Gunston J, Salmond C, et al. Atlas of socioeconomic deprivation in New Zealand NZDep2006. Wellington, New Zealand: Ministry of Health, 2008.

27. Ashwell M, Hsieh S. Six reasons why the waist-to-height ratio is a rapid and effective global indicator for health risks of obesity and how its use could simplify the international public health message on obesity. Int J Food Sci Nutr 2005;56:303-7.

28. Ministry of Health. Food and Nutrition Guidelines for Healthy Children and young People (aged 2-18 years): a background paper. Wellington, New Zealand: Ministry of Health, 2010.

29. Rollnick S, Miller WR, Butler CC. Motivational interviewing in health care: helping patients change behavior. New York, NY: Guilford Press, 2008

30. Landis JR, Koch GG. The measurement of observer agreement for categorical data. Biometrics 1977;33:159-74.

31. Wessel I, van der Kooy $\mathrm{P}$, Merckelbach $\mathrm{H}$. Differential recall of central and peripheral details of emotional slides is not a stable phenomenon. Memory 2000;8:95-109.

32. Touryan SR, Marian DE, Shimamura AP. Effect of negative emotional pictures on associative memory for peripheral information. Memory 2007;15:154-66.

33. Houts PS, Bachrach R, Witmer JT, et al. Using pictographs to enhance recall of spoken medical instructions. Patient Educ Couns 1998;35:83-8.

34. He M, Piché L, Clarson CL, et al. Childhood overweight and obesity management: a national perspective of primary health care providers' views, practices, perceived barriers and needs. Paediatr Child Health 2010;15:419-26.

35. Jelalian E, Boergers J, Alday CS, et al. Survey of physician attitudes and practices related to pediatric obesity. Clin Pediatr (Phila) 2003;42:235-45.

36. Ariza AJ, Laslo KM, Thomson JS, et al. Promoting growth interpretation and lifestyle counseling in primary care. $J$ Pediatr 2009;154:596-601.

37. Bradshaw PW, Ley P, Kincey JA. Recall of medical advice: comprehensibility and specificity. Br J Soc Clin Psychol 1975;14:55-62.

38. Miller W, Rollnick S. Motivational interviewing: preparing people for change. 2nd edn. New York, NY: Guildford Press, 2002.

39. McDonald-Miszczak L, Neupert SD, Gutman G. Younger-old and older-old adults' recall of medication instructions. Can J Aging 2005;24:409-17.

40. Kiviniemi MT, Rothman AJ. Selective memory biases in individuals' memory for health-related information and behavior recommendations. Psychol Health 2006;21:247-72. 